\title{
¿Fundar una comunidad después del crimen? Anotaciones a un texto de Claudia Hilb*
}

Diego Tatián Universidad Nacional de Córdoba - CONICET

I. La pregunta "¿cómo fundar una comunidad después del crimen?" enuncia un problema filosófico y político - explorado asimismo de modo diverso por el derecho, la ética, la antropología, la tragedia...que la Argentina transita desde hace treinta años, en el curso de los cuales ha motivado una reflexión intensa acerca de las condiciones que permiten una reconstitución y una restitución de la vida colectiva, después del crimen. La hondura del dolor abierto desde entonces ha movilizado una paciente tarea en común orientada a la reparación, y también una búsqueda de comprensión que ha vuelto inmediatas y vívidas grandes piezas de la cultura - Antígona, Hamlet, el Evangelio...con las que las generaciones humanas de diferentes tiempos han

* Bajo el título "Justicia, Reconciliación, Perdón. ¿Cómo fundar una sociedad después del crimen?", una versión reducida de este artículo se halla publicada en Julia Smola, Claudia Bacci y Paula Hunziker (editoras), Lecturas de Arendt. Diálogos con la literatura, la filosofia y la política, editorial Brujas, Córdoba, 2012, pp. 191-205. Más extensa, la versión última del texto que he tomado por referencia conserva solo la segunda parte del título: “¿Cómo fundar una comunidad después del crimen?". 
procurado desvanecer o menguar el sinsentido del sufrimiento, es decir han procurado conferirle un significado poniéndolo en una narración.

¿Cómo fundar una sociedad después del crimen? La celebración del banquete totémico, según la conocida Urszene de Tótem y tabú en la cual los hermanos que se habían aliado para asesinar al padre devoran su cuerpo con el propósito de apropiarse de su fuerza, habría dado inicio a la política, la ética, la religión y a la sociedad misma. También al arrepentimiento "sentido en común" y a los dos tabúes que fundan la comunidad de los hombres: la prohibición de matar y de cometer incesto. De manera que - concluye Freud - la sociedad "descansa en la culpa compartida por el crimen perpetrado en común; la religión, en la conciencia de culpa y el arrepentimiento subsiguiente" ${ }^{1}$. La persistencia y la actualidad de este episodio arquetípico que acompaña la aventura colectiva de los hombres a lo largo de su tránsito por la historia, ilumina tal vez ciertas zonas oscuras por las que atraviesan las sociedades empíricas y la conciencia compartida frente a algunas circunstancias, pero no da cuenta acabadamente de nuestro interrogante, cuyo objeto no es solo la influencia que ejercen los muertos sobre la comunidad de los vivientes, sino el daño que portan los sobrevivientes; la relación de éstos consigo mismos y con quienes han sido los autores y los perpetradores de ese daño.

II. La reflexión acerca del carácter político del perdón y la reconciliación que, bajo la pregunta "¿Cómo fundar una comunidad después del crimen?", elabora el texto de Claudia Hilb que ahora nos ocupa - discutible en el mejor sentido de la palabra-, considera temas de enorme relevancia para sociedades marcadas por daños irreparables que no solo deben establecer una paz sino también producir una comprensión y activar la justicia —o más precisamente un castigo-, que en rigor jamás restablece la justicia, ni la produce y cuya función es puramente negativa: evitar los efectos insoportables de la impunidad. Al mismo tiempo, la puesta en relación de la "justicia", la comprensión y la paz se halla acosada por condiciones políticas, culturales, jurídicas

${ }^{1}$ Sigmund Freud, "Tótem y tabú", en Obras completas XIII, Amorrortu, Buenos Aires, 1994, p. 142-148. 
o lingüísticas que, de permanecer intactas, permitirían la reproducción o la repetición del "crimen". El proceso democrático argentino no solo estuvo orientado por una voluntad institucional de reparación jurídica en relación al pasado, sino también por una preocupación por el futuro común que halló su cifra más precisa en una simple locución adverbial: "Nunca más", expresión que designa hasta hoy la desembocadura de una militancia extraordinaria sostenida por uno de los movimientos de derechos humanos más importantes y persistentes en el mundo entero.

Quisiera comenzar por la pregunta misma, e interrogarla a su vez, en sus tres términos: ¿fundar una comunidad?; ¿fundar una comunidad? ¿fundar una comunidad? La pregunta original [“¿Cómo fundar...?”], en efecto, encierra presupuestos no menores, el principal de los cuales es que una comunidad - se entiende aquí: que incluya a quienes han sido objeto de crímenes atroces y quienes los perpetraron - es posible, y es deseable. Si el problema planteado es "cómo hacerlo", se da por descontado, en primer lugar, que esa comunidad no es inevitable, necesaria ni imposible sino una posibilidad, y en segundo lugar que es una posibilidad deseable.

En mi opinión esa comunidad "después del crimen" no es posible, ni es deseable sin las mediaciones necesarias, que no son únicamente narrativas. Sí es posible la mera coexistencia en una misma ciudad de personas que han cometido crímenes atroces - en la medida en que hayan quedado impunes y sus perpetradores libres-, y las víctimas de esos crímenes, que jamás —o muy excepcionalmente- aceptarían la vía de una amnistía como forma de restituir lo común con quienes torturaron y desaparecieron a sus hijos o a sus padres. Esa coexistencia no podría llevar el nombre de comunidad.

Una observación inmediata que cabría formular en relación a nuestro interrogante sería ésta: a diferencia del arquetipo totémico del banquete fraternal que fragmenta el fundamento hasta entonces monárquico del padre (o cualquier otra variante del mito de la fundación), una sociedad dada que emerge del crimen no puede ser, propiamente, fundada - como si esta decisión de fundar pudiera hacer tabula rasa de una historia abierta de hechos dramáticos por los que una población se halla capturada, a veces capturada hasta la demencia-, 
sino siempre intervenida, transformada, reestablecida, resguardada, enmendada. Después de la dictadura - y hasta ahora - la sociedad argentina no se vio tanto confrontada con el problema de cómo comenzar, sino más bien con la pregunta por cómo seguir y por las inmensas dificultades que en esta consecución comporta la herencia social del crimen.

Por ello, no es irrelevante la adopción del pronombre indefinido una, cuyo referente - la "comunidad" en cuestión - es mentado en la pregunta como si se tratase de algo indeterminado y no como una sociedad dañada muy concreta, confrontada con la necesidad de hacer algo consigo misma tras la violencia. La pregunta bajo la que yo pondría el problema - aunque filosóficamente menos interesante y aunque desmesurada en su formulación - sería esta:

¿cuáles acciones jurídicas, políticas y narrativas es necesario que la sociedad argentina lleve adelante para contrarrestar los efectos del Terror que dañan - de manera irreversible en lo profundo- los cuerpos, los vínculos y la vida misma de muchos de sus miembros, habida cuenta de una historia específica de impunidades, en modo de crear las condiciones de posibilidad de una democracia más extensa y más intensa, ininterrumpida en el futuro - $\mathrm{o}$ dicho negativamente: para impedir en cuanto sea posible el resurgimiento del Terror ejercido desde el Estado-?

El texto sobre "¿Cómo fundar una comunidad después del crimen?” parte de discriminar de manera que no es obvia el anhelo social y político de castigo a los responsables de delitos considerados contra la humanidad, respecto de un conjunto de conceptos — verdad, comprensión, arrepentimiento, perdón, reconciliación, capacidad de pensar y de juzgar...-, que serían impedidos por el castigo efectivo o sacrificados a él. Sin embargo, en mi opinión el proceso judicial no impide la verdad, ni la comprensión ni el arrepentimiento (tampoco la comprensión ni el perdón abjuran necesariamente del castigo), ni es la razón por la que "ha sido imposible para represores y guerrilleros revisar su propia acción", ni la causa por la que, después de tantos años, no contemos con la palabra de los victimarios sobre el destino de las 
víctimas, cuyo esclarecimiento sería de tanta importancia para sus familiares.

III. La conjetura de que los militares argentinos se hubieran arrepentido de sus crímenes de haberse producido un proceso semejante al de Sudáfrica - y que además ese proceso hubiera favorecido un relato verídico de los victimarios - no resulta evidente; de hecho, cuando las leyes de punto final y obediencia debida se hallaban vigentes, se realizaron juicios por la verdad histórica sin que se obtuviera de ellos nada interesante ni diferente. De igual modo, salvo excepciones, entre los protagonistas de las organizaciones armadas de izquierda casi no hubo un proceso de revisión de sus acciones (esa revisión e incluso el arrepentimiento se produjo más entre quienes participaron en la lucha política que entre quienes fueron protagonistas directos de la lucha armada) aunque desde hace mucho no están sometidos a procesos judiciales.

La discusión que propone Claudia Hilb - como siempre que una reflexión llega al núcleo de un problema, que en este caso es filosófico, político y también biográfico- pone en marcha interrogantes que no objetan necesariamente la argumentación central sino más bien dan prueba de su fecundidad: ¿por qué no universalizar la vía de una reconciliación que restaure la comunidad prescindiendo del castigo a toda clase de delitos comunes - leves o atroces - y restringirla solo a casos de crímenes "asociados a un objetivo político"? ¿Por qué no extender la tarea de crear condiciones para una reconciliación entre delincuentes y víctimas de cualquier tipo de hechos criminales que suceden todos los días, condiciones de una reconciliación que únicamente pasaran por el tamiz del lenguaje y prescribieran la obligación de un relato verídico que confronte al delincuente consigo mismo en el modo de una inscripción pública de sus actos criminales en una narración, con total prescindencia del sistema punitivo?

¿Y por qué dificultades y de qué orden Hannah Arendt no consideró pertinente su reflexión acerca del perdón y de la reconciliación para el caso de Adolf Eichmann, sino más bien por el contrario - aunque diferenciándose en su argumentación de los jueces israelíes que llevaron adelante el proceso de Jerusalén — justificó en la célebre página final de 
su "reporte" la condena a muerte de quien se presentaba a sí mismo como un simple "técnico", cuyo trabajo había tenido por efecto el exterminio de millones de judíos? ${ }^{2}$ ¿Nos conduciría una perspectiva arendtiana a perdonar a Eichmann, en el caso contrafáctico de que su relato durante el juicio en lugar de haber estado inscripto en la banalidad, la mala fe, la cobardía y la estupidez, hubiera ofrecido un arrepentimiento verdadero ante la opinión pública mundial? ¿Por qué, en rigor, "ningún miembro de la raza humana puede desear compartir la tierra" con él? Y a la inversa: ¿por qué no sería aplicable a quienes ejercieron el Terrorismo de Estado en la Argentina, la misma conclusión a la que llega Arendt en relación a Eichmann? ${ }^{3}$.

La primera cuestión remite a la discusión que plantea la posición abolicionista, cuya variante más radical desestima el castigo —en particular el encierro penitenciario - como respuesta a delitos de cualquier índole (incluso los de lesa humanidad), y ha producido un conjunto de trabajos de mucho interés, cuya consideración nos desviaría de nuestro objeto y no sería pertinente - aunque sí lo es la pregunta de fondo: ¿por qué no extender las condiciones de reconciliación y de perdón a delitos comunes, etc.?-

El segundo problema - referido a los límites del perdón y de la reconciliación - remite a la pregunta por lo imperdonable y lo irreconciliable, que a su vez convoca el motivo kantiano del "mal radical", reelaborado por Arendt en su reflexión acerca del totalitarismo. Esta última temática no es impertinente para nuestro asunto. E1 Terrorismo de Estado argentino no fue simplemente ejecutado por actores que perseguían un objetivo político y que en ese propósito no

${ }^{2}$ Hannah Arendt, Eichmann en Jerusalén. Un estudio sobre la banalidad del mal, Lumen, Barcelona, 2000, pp. 419-421.

3 "Y del mismo modo que tú apoyaste y cumplimentaste una política de hombres que no deseaban compartir la tierra con el pueblo judío ni con ciertos otros pueblos de diversa nación - como si tú y tus superiores tuviérais el derecho de decidir quién puede y quién no puede habitar el mundo-, nosotros consideramos que nadie, es decir, ningún miembro de la raza humana puede desear compartir la tierra contigo. Esta es la razón, la única razón por la que has de ser ahorcado" (Ibid., p. 421). 
¿Fundar una comunidad después del crimen? Anotaciones...

sabían lo que hacían, antes bien ni sus procedimientos ni el relato que los justificaba - hasta hoy intacto - estaban exentos de estupidez y de maldad. De existir lo imperdonable - actos imperdonables-, los sujetos que los perpetraron solo podrían obtener perdón en una dimensión ética, o religiosa, mas no jurídica —y esto relativamentepues quienes en su intimidad podrían perdonar ya no están, y los familiares y compañeros de quienes ya no están podrían, a lo sumo, perdonar por su dolor pero no por el dolor de quien ya no puede perdonar. No es posible perdonar por otro. En cuanto al perdón jurídico, no es tal si se decreta de manera externa y contra la voluntad explícita de quienes portan un daño - no obstante existir un mecanismo constitucional que así lo prevea-, ni se impone desde el Estado, y por ello en mi opinión no puede tener un estatuto solo jurídico. Puede ser concedido por voluntad y decisión de quien ha sido objeto de un daño y se encuentra afectado por él. Si ocurre lo primero sin lo segundo, la amnistía será indistinguible de la impunidad.

Ciertos actos resisten ser elaborados por un puro procedimiento voluntario de verdad, y mucho más por una decisión gubernamental abstracta que privilegie la conveniencia pragmática de cerrar el pasado como si no hubiera existido, a partir de considerar la imposibilidad $-\mathrm{O}$ la interminabilidad - de su revisión jurídica y política. Más bien lo imposible es que esa decisión revista eficacia, y que la sociedad sobre - contra - la que se aplica no quede capturada en la injusticia (concepto que, a diferencia del de justicia, comprendemos muy bien) e inmersa en una constante irrupción de síntomas sociales de autodestrucción y de violencia, en los que se manifestaría, de manera imprevisible, el daño.

IV. La alternativa entre la Verdad y la Justicia como opciones "ejemplares" para salir del crimen, así como la comparación misma entre la vía sudafricana y la vía argentina en tanto experiencias que afrontan de diferente modo una circunstancia que sería similar, no obstante su productividad filosófica, encuentran limitaciones que resultan a mi entender de no considerar con la necesaria prioridad subjetividades políticas e historias que son completamente distintas -y en último término por considerar que se trata de "opciones"- - La sugerencia de recurrir al "contraejemplo sudafricano" para "iluminar 
una zona oscura de la escena argentina" no me parece exenta de equívocos. Esa oposición - o comparación - permitiría "preguntarnos acerca del precio que la opción por la justicia, opción notable, pagó sin embargo, en su cristalización posterior, en la Argentina, en lo que concierne al restablecimiento de una escena pública asentada en la asunción, por parte de sus actores, de una responsabilidad común". La pregunta inversa - que el texto no se formula - acerca del "precio" de la "opción" sudafricana por la amnistía probablemente revelaría que fue mucho más alto y sus "zonas oscuras" mucho más oscuras (más aún: resulta improbable que en Sudáfrica se haya verificado efectivamente un proceso social conformado por un real reconocimiento del crimen, el arrepentimiento, el perdón y finalmente la reconciliación).

Sin embargo, esta pregunta inversa me parece igualmente equívoca por cuanto la comparación misma — que por lo demás no es nunca una mera comparación - lo es. Y en todo caso, más ajustada resultaría esa comparación con la manera en que los países latinoamericanos - cuya historia reciente es similar a la nuestra- elaboraron (o dejaron de hacerlo) los efectos inferidos a sus sociedades por sus respectivas dictaduras militares, que actuaban en coordinación por el Plan Cóndor. Una comparación, pues, con el "contraejemplo" chileno más bien que con la vía sudafricana acaso revelaría conclusiones de mayor pertinencia para la autorreflexión política argentina, por cuanto la deriva chilena (con sus variantes, también pueden considerarse aquí comparativamente las transiciones democráticas en Uruguay, Paraguay o Brasil) es la alternativa real - y no la sudafricana - que hubiera podido adoptar la democracia argentina en 1983 - de hecho esa alternativa era la que entonces explicitaba la propuesta electoral del Partido Justicialista-, y continuado hasta ahora. En cambio, la política argentina de derechos humanos es invocada como una constante referencia por muchas fuerzas democráticas en Latinoamérica, y ha ejercido una influencia no menor en los comparativamente escasos avances para desactivar los efectos del terrorismo de Estado en los países de la región.

Más que afirmar la "opción por la Verdad" y la "opción por la Justicia" como alternativas, y más que establecer una "comparación" entre las marchas y contramarchas de la democracia argentina en 
relación al Terrorismo de Estado y el proceso sudafricano impulsado por Mandela - que no es meramente descriptiva y no está exenta de efectos políticos en el momento en el que se producen juicios en todo el país largamente esperados por los organismos de derechos humanos-, me inclinaría a remarcar la singularidad incomparable y la excepcionalidad del proceso político argentino en el modo de elaborar su propia historia reciente. Y secundariamente me pregunto si la "opción" sudafricana por la amnistía (condicionada a la verdad) no es una vía - la única posible en este caso - impulsada por Mandela con inteligencia habida cuenta las condiciones de impotencia política, tras el apartheid, para una sanción jurídica de crímenes atroces.

Mi hipótesis por tanto es diferente, si no contraria, a la que se sugiere en el texto de Claudia Hilb: la Argentina es un país más justo y más verdadero a la vez, por el hecho —singular en la historia latinoamericana hasta entonces y hasta ahora- de haber asumido la intermitente decisión política, social y judicial — siendo imprescindibles las tres - de condenar los crímenes del Terror ejercido desde el Estado entre 1974 y 1983 (escribo este comentario cuando se lleva adelante el juicio por la masacre de Trelew, por lo que debería retrotraerse a 1972 el año en el que tiene inicio el Terror estatal que ahora se juzga). Los hitos fundamentales de esa decisión fueron el juicio de 1985 a las Juntas que gobernaron el país durante la dictadura, y la actual reapertura de los juicios a crímenes contra la humanidad desde la anulación por inconstitucionales de las llamadas leyes del perdón en 2004. No se trata, según creo, de hechos que puedan contraponerse, como si los juicios de los años ochenta estuvieran dotados de "enormes virtudes originarias" que la actual "insistencia" en la vía judicial hubiera perdido, "cristalizado" o mal-versado, y cuyo solo efecto fuera el bloqueo de una posible reconciliación (ajustado y prudente, el artículo de Claudia Hilb no afirma directamente esta contraposición pero, si no leo mal, la sugiere). Antes bien, ambos episodios establecen una línea de continuidad indudable - que el actual gobierno en muchas ocasiones omite, como omite otras conquistas sociales obtenidas en los años ochenta que antecedieron y en cierto modo permitieron la radicalización de derechos en curso- y deben ser considerados como partes de un 
mismo proceso de consolidación democrática. Si el segundo debe mucho en su posibilidad al primero (y a la valentía del presidente Alfonsín de afrontar la vía institucional de la justicia no obstante la debilidad objetiva de la democracia recién recuperada para emprender juicios de semejante magnitud política, seguramente los más importantes de la historia institucional argentina), a la vez continúa lo que fue interrumpido por la extorsión militar que obligó al Parlamento a sancionar las leyes llamadas del perdón.

Esta laboriosa tarea de la justicia no ha impedido ni bloqueado la verdad, sino recabado, también laboriosamente, las — sin duda insuficientes - informaciones de las que se disponen, y colaborado con la recuperación de ciento siete de las aproximadamente quinientas identidades de niños robados, que con toda probabilidad hubieran quedado ocultas para siempre si la deriva argentina hubiera prosperado hacia una amnistía en cualquiera de sus modalidades: autoamnistía, amnistía extorsiva o amnistía condicionada a la verdad (en una variante semejante a la sudafricana en 1995).

V. La capacidad de pensar y de juzgar el pasado reciente y de formular las preguntas correctas con relación a él — que es en efecto una capacidad de no sucumbir a la mera reproducción, a la repetición mecánica y a la consigna necia - se libera gracias a - y se conjuga con- la paciencia de un trabajo cuando obtiene sus frutos institucionales y sociales y permite así al pensamiento y a la conversación pública adoptar finalmente una forma distinta del reclamo y la demanda.

¿Cómo es posible liberar la capacidad de juzgar de su captura en la demanda? En mi opinión solo el cumplimiento de la accidentada vía judicial emprendida por la democracia argentina hace veintisiete años y el consiguiente castigo de quienes fueron los responsables de la decisión de "aniquilar" y exterminar desde el Estado a los miembros de las organizaciones armadas y otros opositores políticos por fuera de todo marco legal, es la única posibilidad de la que disponemos para crear las condiciones que permitan la tarea colectiva de comprender por fuera de clichés y frases hechas; la tarea de emprender un relato menos simple, diferente del que presenta las cosas como si se tratara "del Mal que se 
abatió sobre el Bien"; la tarea de indagar la responsabilidad de la violencia insurreccional en el establecimiento del Terror, y desarrollar de otro modo la pregunta acerca de "cómo, por qué, pudo suceder lo que nunca debió haber sucedido". Esas tareas y esta pregunta serían a mi entender imposibles — social y políticamente imposibles - de haber persistido una situación de impunidad decidida desde el Estado por acción o por inacción (incluso si esa decisión llegara a ser resultado de una consulta plebiscitada).

El castigo compensa de algún modo -insuficiente y necesario modo- a víctimas y sobrevivientes inmersos en el continuo de la tortura y el dolor, que son esencialmente atemporales y continúan sucediendo sin perder su inmediata intensidad, al punto de que - cientos de testimonios de familiares así lo corroboran- no se inscriben ni suceden en el tiempo sino al revés: el tiempo y lo que trae su cotidiano transcurso suceden en el dolor que, por tanto, no pasa — en sentido cronológico de la palabra- 